\title{
CHARACTERIZATION OF SOLVENT-FRACTIONATED MUSTARD OIL BY HIGH PERFORMANCE LIQUID CHROMATOGRAPHY
}

\author{
M. A. Alim, J. H. Lee ${ }^{1}$, C. R. Lee' ${ }^{1}$ C. C. Akoh ${ }^{2}$ and K. T. Lee ${ }^{1}$ \\ Department of Food Technology and Rural Industries, Bangladesh Agricultural \\ University, Mymensingh-2202, Bangladesh
}

\begin{abstract}
Mustard oil (MO) was fractionated at low temperature with acetone. The liquid fraction obtained at $-24^{\circ} \mathrm{C}$, showed higher levels of oleic $(24.7 \%)$ and linoleic $(22.0 \%)$ acids, and lower level of erucic acid (24.5\%) compared to other fractions. The lowest temperature $\left(-24^{\circ} \mathrm{C}\right)$ was most effective for lowering the level of erucic acid through crystallization of triacylglycerol (TAG) molecules. One purpose of this study was to obtain erucic acid reduced fractions because erucic acid has undesirable effect on human health. The result suggested that erucic acid could be separates as solid fraction thereby better reduction of erucic acid would be possible at lower temperature.
\end{abstract}

Key Words: Mustard oil, Erucic acid, Crystallization, Triacylglycerol

\section{INTRODUCTION}

The people of India especially eastern and northern parts of India, Nepal and Bangladesh commonly use mustard oil (MO). MO has a strong smell, hot nutty taste, pungent and sulphury odor, and much used for cooking that are valuable for human health by reducing the risk of colon tumor incidence and multiplicity as compared to the dietary corn and fish oil (Dwivedi et al., 2003). MO may enhance protective effects in the patients with acute myocardial infarction possibly owing to presence of omega-3-fatty acid (Singh et al., 1997). MO also has high amount of mono-unsaturated fatty acids and a good ratio of polyunsaturated fatty acids, which is good for heart. MO mostly contains erucic, oleic, linoleic and a-linolenic acid (Dwivedi et al., 2003; Webster, 1998; Pritchard, 1991; Fernandez-Escober, 1988). The oil makes up about $24-40 \%$ of the mustard seeds, which is characterized by the presence of higher level of erucic acid and it has undesirable effects on health when consumed in large amounts and shown serious pathological changes in the heart and skeletal muscles after feeding with high erucic acid rapeseed oil in animals (Aaes-Jorgensen, 1972). So, modification is needed for changing their properties (physical and chemical). Fractionation is one of the common processes that may be used to modify the thermal properties of lipids. It provides fractionated parts with desired fatty acids. After fractionation, each fractionated phase would be enriched in either higher or lower melting TAG species from the original lipids. Among different fractionation methods, solvent fractionation with low temperature is the most efficient one and the used solvent

\footnotetext{
${ }^{1}$ Department of Food Science and Technology, Chungnam National University, Taejeon 305-764, South Korea

${ }^{2}$ Department of Food Science and Technology, The University of Georgia, Athens, GA 30605, USA
} 
such as hexane, acetone, isopropyl alcohol and their mixture increases the yields of fractionated products at low temperature (Hamm, 1995). Usually, the liquid phase contains more TAG molecules with unsaturated fatty acids while the solid phase contains more saturated TAG molecules (Chong, 1992; Lee and Foglia, 2001; Mayamol et al., 2004). The objectives of this study were to prepare erucic acid reduced TAG fractions from MO; to analyze total and positional distribution of fatty acid content of $\mathrm{MO}$ and fractions obtained from MO.

\section{MATERIALS AND METHODS}

\section{Materials}

Mustard oil (MO) was supplied from Agricultural Marketing Co. Ltd. (Dhaka, Bangladesh). The lipase (Lipozyme TL IM) used was the immobilized preparation of a 1,3-specific produced from Thermomyces lanuginosus, obtained from Novozymes A/S (Bagsvaerd, Denmark). Having specific activity is $175 \mathrm{IUN} / \mathrm{g}$ density, $0.54 \mathrm{~g} / \mathrm{ml}$ width, 0.3-1.0 mm particle diameter and $5 \mathrm{w} / \mathrm{w} \%$ of water content. Acetone, n-hexane, 2propanol, heptadecanoic acid, capric acid and acetic acid were obtained from SigmaAldrich Chemical Co. (St. Louis, MO, USA). The pancreatic lipase was purchased from Sigma Chemical Co. (St. Louis, MO, USA).

\section{Fractionation of MO}

$\mathrm{MO}(300 \mathrm{ml})$ and acetone $(1500 \mathrm{ml})$ were mixed $($ ratio $=1: 5, \mathrm{v} / \mathrm{v})$ together in a 3-L conical flask (Yu et al., 2006). The conical flask was placed in a deep freezer at different temperatures $\left(-10,-16\right.$ and $\left.-24^{\circ} \mathrm{C}\right)$ for fractionation. After $24 \mathrm{~h}$, the liquid phase was separated from the solid phase by decanting, and acetone was completely evaporated from liquid or solid phase of MO using a rotary vacuum evaporator and dried with nitrogen. Liquid and solid phases were used for further study.

\section{Fatty acid composition}

TAG from MO, liquid and solid phase of fractionated MO were separated on a silica gel $60 \mathrm{~F}_{254}$ plate developed with hexane/diethyl ether/acetic acid (50/50/1, v/v/v) and detected under short $(254 \mathrm{~nm})$ wavelengths. TAG band was scraped off into a screwcapped tube and methylated by $6 \% \mathrm{H}_{2} \mathrm{SO}_{4}$ in methanol for $1 \mathrm{~h}$ at $70^{\circ} \mathrm{C}$. Fifty $\mu \mathrm{l}$ heptadecanoic acid (C17:0, $1 \mathrm{mg} / \mathrm{ml}$ in hexane) as an internal standard was also added in the tube. After putting on ice immediately, $2 \mathrm{ml}$ hexane was added and vortexed for 30 sec. The upper layer was passed through an anhydrous sodium sulfate column, and dried with nitrogen. Fatty acids were analyzed by gas chromatography (GC, Agilent, HP 6890 Series, Avondale, PA), accompanied with auto-injection and flame-ionization detection and a fused-silica capillary column (SP-WAX, $60 \mathrm{~m} \times 0.25 \mathrm{~mm}$ id, Supelco, Bellefonte, PA). Temperature gradient was $100^{\circ} \mathrm{C}$ to $220^{\circ} \mathrm{C}$ with an increasing rate $4^{\circ} \mathrm{C} / \mathrm{min}$. Nitrogen was used as a carrier gas with flow rate $52 \mathrm{ml} / \mathrm{min}$ with split mode (50:1). The temperature of injector and detector were 250 and $260^{\circ} \mathrm{C}$, respectively. All analyses and quantification were conducted in duplicate. 


\section{Positional fatty acid composition}

The MO, liquid and solid phase of fractionated MOs $(7 \mathrm{mg})$ were taken in a test tube. Seven $\mathrm{ml}$ of Tris- $\mathrm{HCl}$ buffer (pH 7.6), $1.75 \mathrm{ml}$ of $0.05 \%$ bile salt, $0.7 \mathrm{ml}$ of $2.2 \% \mathrm{CaCl}_{2}$ and 7 $\mathrm{mg}$ of pancreatic lipase were mixed and vortexed for $30 \mathrm{sec}$. Other steps were followed as described by Lee and Akoh (1996). The hydrolytic products were separated on silica gel $60 \mathrm{~F}_{254}$ plate with a solvent system of hexane: diethyl ether: acetic acid (50:50:1, v/v/v). The band of monoacylglycerol was scrapped off for methylation and analyzed by GC. Percentage of fatty acid at sn-1,3 position was calculated by the formula : sn-1,3 $(\%)=(3 \mathrm{~T}$ $-\mathrm{sn}-2) / 2$ where $\mathrm{T}$ is the total fatty acid contents of $\mathrm{MO}$, liquid and solid phase of $\mathrm{MO}$, respectively.

\section{High-performance liquid chromatography (HPLC)}

The separation of TAG species in MO and the fractionated MO was conducted by reversed-phase high performance liquid chromatography (AOCS, 1990). The HPLC system consisted of Yonglin SP930D dual pump (Yonglin, Anyang, Korea) with Sedex 75 evaporative light-scattering detector (ELSD, Sedere, Alfortvill, France). Each sample (5 $\mathrm{mg}$ ) was dissolved in chloroform $(10 \mathrm{ml})$. Twenty micro liters of filtrated sample was injected by auto sampler (Model 816, Young Lin Instrument Co. Ltd, The Netherlands) on Nova-Pak C18 (3.9 x $150 \mathrm{~mm}$, Milford, MA) column. The operation temperature of ELSD was $40^{\circ} \mathrm{C}$ and nitrogen was used as a nebulizing gas at a pressure of 2.2 bars. The mobile phase was acetone/acetonitrile at a flow rate of $0.5 \mathrm{ml} / \mathrm{min}$. The solvent flow started with a ratio of $60: 40(\mathrm{v} / \mathrm{v}$, acetone/acetonitrile) for $10 \mathrm{~min}$, jumping to 100:0 (v/v) in $10 \mathrm{~min}$, holding for $5 \mathrm{~min}$, decreasing to 60:40 (v/v) in $5 \mathrm{~min}$ and finally holding for $10 \mathrm{~min}$.

\section{Statistics}

The statistical analysis system (SAS, 2002) was used to perform statistical analysis. Duncan's multiple range tests was performed on the means of values. The tested significance was considered at $5 \%$ level.

\section{RESULTS AND DISCUSSION}

\section{Separation of triacylglycerol (TAG) molecules}

At low temperature, the separation of TAG molecules is facilitated by the presence of solvent depending on their melting points. Reason was that TAG molecules form more stable crystals within a short period of time with solvents. In this study, acetone is used as a suitable solvent for TAG fractionation of $\mathrm{MO}$ at low temperatures $\left(-10,-16\right.$ and $\left.-24^{\circ} \mathrm{C}\right)$. $\mathrm{MO}$, liquid and solid fractions obtained from MO was analyzed by reverse-phase HPLC. Fig. 1 shows the typical reverse-phase HPLC chromatograms of liquid (Fig. 1 A) and solid (Fig. $1 \mathrm{~B}$ ) fractions obtained from $\mathrm{MO}$ using fractionation procedure at $-16^{\circ} \mathrm{C}$ and $\mathrm{MO}$ (Fig. $1 \mathrm{C}$ ). Based on peak number (area \%) of the TAG molecules, seven peaks were taken in consideration. The area \% of each peak from each species is presented for qualitative comparison (Table 1). 
Table 1. Levels of triacylglycerols in mustard oil (MO) and fractionated mustard oil obtained by high-performance liquid chromatography (HPLC)

\begin{tabular}{l|c|c|c|c|c|c|c|c}
\hline Species & $\begin{array}{c}\text { Peak 1 } \\
(\text { area \%) }\end{array}$ & $\begin{array}{c}\text { Peak 2 } \\
(\text { area \%) }\end{array}$ & $\begin{array}{c}\text { Peak 3 } \\
(\text { area \% })\end{array}$ & $\begin{array}{c}\text { Peak 4 } \\
\text { (area \%) }\end{array}$ & $\begin{array}{c}\text { Peak 5 } \\
(\text { area \% })\end{array}$ & $\begin{array}{c}\text { Peak 6 } \\
\text { (area \%) }\end{array}$ & $\begin{array}{c}\text { Peak 7 } \\
(\text { area \%) })\end{array}$ & $\begin{array}{c}\text { Yield } \\
(\text { wt \% })\end{array}$ \\
\hline MO & - & - & $1.2^{\mathrm{f}}$ & $6.7^{\mathrm{d}}$ & $31.0^{\mathrm{c}}$ & $38.0^{\mathrm{c}}$ & $23.1^{\mathrm{c}}$ & - \\
$-24 \mathrm{~L}^{*}$ & $2.2^{\mathrm{b}}$ & $9.0^{\mathrm{a}}$ & $19.8^{\mathrm{a}}$ & $30.7^{\mathrm{a}}$ & $28.7^{\mathrm{g}}$ & $8.5^{\mathrm{f}}$ & $1.1^{\mathrm{g}}$ & $6.6^{\mathrm{f}}$ \\
$-24 \mathrm{~S}$ & - & - & $1.5^{\mathrm{d}}$ & $6.1^{\mathrm{e}}$ & $30.8^{\mathrm{d}}$ & $38.6^{\mathrm{b}}$ & $23.0^{\mathrm{d}}$ & $93.4^{\mathrm{a}}$ \\
$-16 \mathrm{~L}$ & $2.4^{\mathrm{a}}$ & $5.1^{\mathrm{b}}$ & $10.7^{\mathrm{b}}$ & $19.4^{\mathrm{b}}$ & $39.4^{\mathrm{b}}$ & $19.0^{\mathrm{e}}$ & $4.0^{\mathrm{f}}$ & $10.0^{\mathrm{e}}$ \\
$-16 \mathrm{~S}$ & - & - & $0.9^{\mathrm{g}}$ & $5.2^{\mathrm{f}}$ & $30.0^{\mathrm{f}}$ & $38.9^{\mathrm{a}}$ & $25.0^{\mathrm{a}}$ & $90.0^{\mathrm{b}}$ \\
$-10 \mathrm{~L}$ & $0.6^{\mathrm{c}}$ & $3.1^{\mathrm{c}}$ & $6.3^{\mathrm{c}}$ & $16.1^{\mathrm{c}}$ & $39.6^{\mathrm{a}}$ & $26.6^{\mathrm{d}}$ & $7.7^{\mathrm{e}}$ & $16.3^{\mathrm{d}}$ \\
$-10 \mathrm{~S}$ & - & - & $1.3^{\mathrm{e}}$ & $5.0^{\mathrm{g}}$ & $30.4^{\mathrm{e}}$ & $38.9^{\mathrm{a}}$ & $24.4^{\mathrm{b}}$ & $83.7^{\mathrm{c}}$ \\
\hline
\end{tabular}

The same letters within column are not significantly different $(\mathrm{p}<0.05)$

* $-24 \mathrm{~L}$ is the liquid fraction obtained by fractionation at $-24^{\circ} \mathrm{C}$. Other fractions are similarly designated

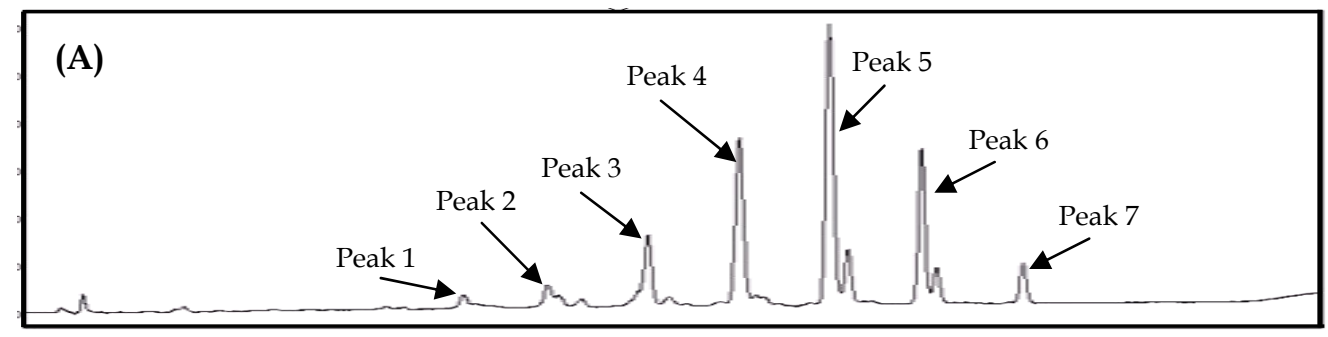

Time

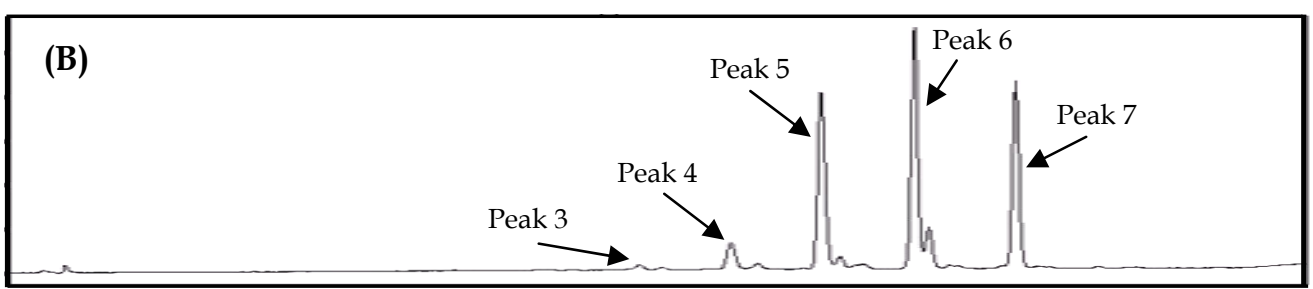

Time

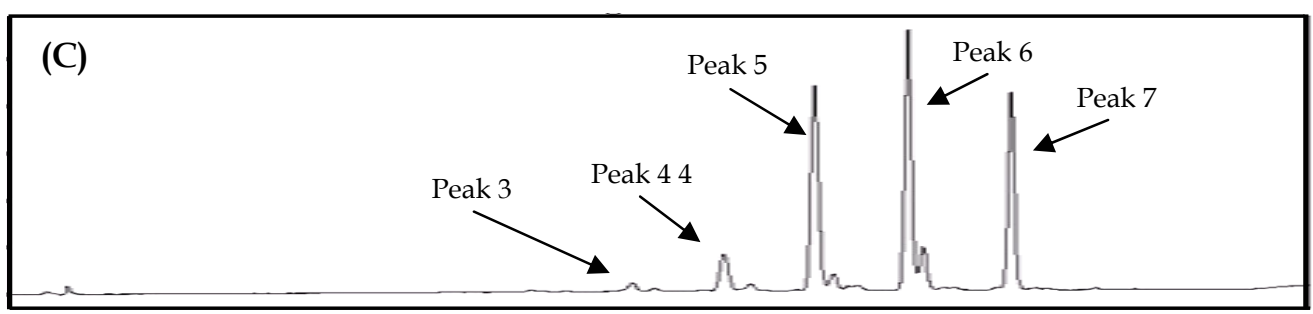

Time

Fig. 1. Typical reverse-phase HPLC pattern of fractionated and non-fractionated mustard oil (A) Liquid fraction, (B) Solid fraction and (C) Mustard oil 
Table 1 indicated that the peak 1 of $-24 \mathrm{~L}$ accounted $2.2 \%$, while $2.4 \%$ was observed for peak 1 of $-16 \mathrm{~L}$. The peak 2 of $-24 \mathrm{~L}$ showed $9.0 \%$ which was higher than those of the peak 2 of $-16 \mathrm{~L}$ and $-10 \mathrm{~L}$. The peak 3 and 4 of $-24 \mathrm{~L}$ accounted higher area percent 19.8 and $30.7 \%$, respectively and significantly higher than those of others. For all solid fractions and neat $\mathrm{MO}$, the peak 5 showed even area percent distribution than those of others. Among all fractions, the peak 6 and 7 of $-24 S,-16 S$ and $-10 S$ accounted higher area percent than those of $-24 \mathrm{~L},-16 \mathrm{~L}$ and $-10 \mathrm{~L}$, respectively. However, TAG molecules in peak 6 and peak 7 are assumed to contain more erucic acid content (C22:1). Comparing the peak area percent between neat $\mathrm{MO}$ and $-24 \mathrm{~L}$, the peak 3 of $-24 \mathrm{~L}$ increased significantly $(\mathrm{p}<0.05)$ by sixteen times and the peak 4 by four and half times, while the peak 6 decreased to four and half and the peak 7 also decreased twenty one times. Therefore, as expected, the low temperature $\left(-24^{\circ} \mathrm{C}\right)$ was the most effective for lowering the levels of erucic acid through crystallization of TAG molecules. Compared to $-24 \mathrm{~L},-24 \mathrm{~S}$ showed higher area $\%$ of peak 5 , 6 and 7. The fractionation yields were $6.6 \%$ of $-24 \mathrm{~L}$ and $93.4 \%$ of $-24 \mathrm{~S}, 10.0 \%$ of $-16 \mathrm{~L}$ and $90.0 \%$ of $-16 \mathrm{~S}$, and $16.3 \%$ of $-10 \mathrm{~L}$ and $83.7 \%$ of $-10 \mathrm{~S}$, respectively (Table 1 ).

Although, it is well recognized that enrichment of unsaturated fatty acid (UFA) could be attained in the liquid fraction rather than the solid fraction. In this study, liquid fraction contained slightly higher content of saturated fatty acids than that of solid fraction but liquid fraction contained lower level of erucic acid for all cases. The results demonstrated that low level of erucic acid fractions would be obtained by fractionation method at low temperature.

\section{Fatty acid composition}

The fatty acid compositions (mol \%) of MO, $-24 \mathrm{~L},-24 \mathrm{~S},-16 \mathrm{~L},-16 \mathrm{~S},-10 \mathrm{~L}$ and $-10 \mathrm{~S}$ are presented in Table 2. The fractionated all solid phase contained little lower levels of total unsaturated fatty acid contents than those of liquid phase and neat MO, while solid fractions showed more erucic acid content (22:1). Liquid fraction obtained at $-24^{\circ} \mathrm{C}$, showed higher levels of oleic $(24.7 \%)$ and linoleic (22.0\%) acids and lower level of erucic acid $(24.5 \%)$ compared to neat MO. Erucic acid content decreased about $43 \%$ at $-24^{\circ} \mathrm{C}$ with a recovery yield of $6.6 \%$ (Table 1 ). For the $-16 \mathrm{~L}$, the erucic acid content was $27.3 \%$. However, the recovery yield of $-16 \mathrm{~L}(10.0 \%)$ was near twice than that of $-24 \mathrm{~L}$. For $-10 \mathrm{~L}$, the erucic acid content and the recovery yield were 36.6 and $16.3 \%$, respectively. Therefore, when the fractionation temperature decreased from -16 to $-24^{\circ} \mathrm{C}$, the erucic acid content in liquid fraction obtained from MO decreased by $2.8 \%$ while the weight recovery decreased to $3.4 \%$. On the other hand, the yield and erucic acid content both increased 6.3 and $12.1 \%$ respectively when fractionation temperature increased from -24 to $-10^{\circ} \mathrm{C}$. Compared to neat $\mathrm{MO}, 18.4 \%$ decreased of erucic acid content was obtained in $24 \mathrm{~L}$. Actually, from the fractionation process, the erucic acid content in all liquid fractions was significantly decreased from that of MO. The lowest erucic acid content was obtained from liquid fractions at $-24^{\circ} \mathrm{C}(-24 \mathrm{~L})$, which was significantly different $(\mathrm{p}<0.05)$ from other liquid fractions obtained from MO. Positional distributions of fatty acids of $\mathrm{MO},-24 \mathrm{~L}$, $-24 \mathrm{~S},-16 \mathrm{~L},-16 \mathrm{~S},-10 \mathrm{~L}$ and $-10 \mathrm{~S}$ are also presented in Table 2. Nutritionally, a higher level of unsaturated fatty acids at sn-2 position is important because it is easily absorbed in the 
human body (Quinlan and Moore, 1993). In -24L, the major fatty acids at sn-2 position were linoleic $(41.0 \%)$, oleic $(28.5 \%)$ and a-linolenic $(24.1 \%)$ acid. However, the content of the fatty acids were somewhat different at sn-1,3 positions, presenting $34.9 \%$ erucic, $22.8 \%$ oleic, $20.9 \%$ a-linolenic and $12.5 \%$ linoleic acid. For the $-16 \mathrm{~L}$, the major fatty acid contents were linoleic $(42.3 \%)$, oleic $(28.2 \%)$ and a-linolenic acid $(26.4 \%)$. The solid fractions at any temperature contained low levels of erucic acid than that liquid fraction at $\mathrm{sn}-2$ positions. In neat $\mathrm{MO}$, the major fatty acid contents at $\mathrm{sn}-2$ position were linoleic $(39.5 \%)$, oleic $(35.4 \%)$ and a-linolenic $(22.6 \%)$ and at sn-1,3 position, the major fatty acids were erucic $(63.7 \%)$, a-linolenic $(15.8 \%)$ and oleic $(8.3 \%)$ acid.

Table 2. Total and positional distribution of fatty acid content of mustard oil (MO) and fractions obtained from MO

\begin{tabular}{|c|c|c|c|c|c|c|c|c|c|c|}
\hline Species & & $16: 0$ & $16: 1$ & $18: 0$ & 18:1 & $18: 2$ & $18: 3$ & 22:1 & $\Sigma \mathrm{SFA}^{¥}$ & $\Sigma$ UFA \\
\hline \multirow[t]{7}{*}{ Total } & MO & $4.0^{\mathrm{e}}$ & $\mathrm{nd}^{\dagger}$ & $1.8^{\mathrm{b}}$ & $17.3^{c}$ & $15.9^{\mathrm{d}}$ & $18.1^{\mathrm{e}}$ & $42.9 \mathrm{c}$ & $5.8^{\mathrm{e}}$ & $94.2^{c}$ \\
\hline & $-24 \mathrm{~L}^{*}$ & $4.7^{\mathrm{b}}$ & $0.8^{\mathrm{a}}$ & $1.3^{\mathrm{e}}$ & $24.7 \mathrm{a}$ & $22.0 \mathrm{a}$ & $22.0 \mathrm{c}$ & $24.5^{\mathrm{f}}$ & $6.0^{\mathrm{d}}$ & $94.0^{\mathrm{d}}$ \\
\hline & $-24 S$ & $3.8^{f}$ & $\mathrm{Nd}$ & $1.7 \mathrm{c}$ & $16.2^{f}$ & $15.1 \mathrm{e}$ & $17.9^{f}$ & $45.3^{a}$ & $5.5 \mathrm{~g}$ & $94.5^{\mathrm{a}}$ \\
\hline & $-16 \mathrm{~L}$ & $5.1^{\mathrm{a}}$ & $0.7 \mathrm{~b}$ & $1.4^{\mathrm{d}}$ & $22.5^{\mathrm{b}}$ & $20.8^{\mathrm{b}}$ & $22.2^{b}$ & $27.3 \mathrm{e}$ & $6.5^{\mathrm{a}}$ & $93.5 \mathrm{~g}$ \\
\hline & $-16 S$ & $4.0^{\mathrm{e}}$ & $\mathrm{Nd}$ & $1.7 \mathrm{c}$ & $16.3^{\mathrm{e}}$ & $15.0^{f}$ & $17.7 \mathrm{~g}$ & $45.3^{\mathrm{a}}$ & $5.7^{f}$ & $94.3^{\mathrm{b}}$ \\
\hline & $-10 \mathrm{~L}$ & $4.4^{c}$ & $0.5^{c}$ & $1.8^{\mathrm{b}}$ & $16.7^{d}$ & $17.5^{c}$ & $22.5^{\mathrm{a}}$ & $36.6^{\mathrm{d}}$ & $6.2^{\mathrm{b}}$ & $93.8^{\mathrm{f}}$ \\
\hline & $-10 S$ & $4.2^{\mathrm{d}}$ & $\mathrm{Nd}$ & $1.9^{a}$ & $15.7 \mathrm{~g}$ & $14.8 \mathrm{~g}$ & $18.2^{\mathrm{d}}$ & $45.2^{\mathrm{b}}$ & $6.1^{\mathrm{c}}$ & $93.9 \mathrm{e}$ \\
\hline \multirow[t]{7}{*}{ sn-2 } & $\mathrm{MO}$ & $0.8^{\mathrm{e}}$ & $\mathrm{Nd}$ & $0.4^{\mathrm{e}}$ & $35.4^{\mathrm{d}}$ & $39.5^{\mathrm{d}}$ & $22.6^{\mathrm{d}}$ & $1.3^{\mathrm{d}}$ & $1.2^{\mathrm{e}}$ & $98.8^{b}$ \\
\hline & $-24 \mathrm{~L}$ & $1.4^{\mathrm{b}}$ & $\mathrm{Nd}$ & $1.3^{\mathrm{a}}$ & $28.5^{f}$ & $41.0^{\mathrm{b}}$ & $24.1^{\mathrm{c}}$ & $3.6^{\mathrm{a}}$ & $2.7 \mathrm{a}$ & $97.3^{\mathrm{f}}$ \\
\hline & $-24 S$ & $0.7^{f}$ & $\mathrm{Nd}$ & nd & $36.3 c$ & $35.5 \mathrm{~g}$ & $22.4^{\mathrm{e}}$ & $1.1^{\mathrm{e}}$ & $0.7^{f}$ & $99.3^{a}$ \\
\hline & $-16 \mathrm{~L}$ & $1.0^{\mathrm{d}}$ & $\mathrm{Nd}$ & $0.4^{\mathrm{e}}$ & $28.2 \mathrm{~g}$ & $42.3^{a}$ & $26.4^{a}$ & $1.7 \mathrm{~b}$ & $1.4^{\mathrm{c}}$ & $98.6^{\mathrm{d}}$ \\
\hline & $-16 S$ & $0.8^{\mathrm{e}}$ & $\mathrm{Nd}$ & $0.5^{\mathrm{d}}$ & $36.8^{\mathrm{b}}$ & $39.2^{\mathrm{e}}$ & $21.7^{\mathrm{f}}$ & $1.0^{\mathrm{f}}$ & $1.3^{\mathrm{d}}$ & $98.7 \mathrm{c}$ \\
\hline & $-10 \mathrm{~L}$ & $2.0^{\mathrm{a}}$ & $\mathrm{Nd}$ & $0.7 \mathrm{c}$ & $31.4 \mathrm{e}$ & $39.9 c$ & $24.4^{\mathrm{b}}$ & $1.6^{c}$ & $2.7 \mathrm{a}$ & $97.3^{\mathrm{f}}$ \\
\hline & $-10 \mathrm{~S}$ & $1.3^{c}$ & $\mathrm{Nd}$ & $0.8^{\mathrm{b}}$ & $36.9 \mathrm{a}$ & $39.0^{\mathrm{f}}$ & $21.2 \mathrm{~g}$ & $0.8 \mathrm{~g}$ & $2.1^{\mathrm{b}}$ & $97.9 \mathrm{e}$ \\
\hline \multirow[t]{7}{*}{ sn-1,3 } & $\mathrm{MO}$ & $5.6^{d}$ & $\mathrm{Nd}$ & $2.5^{a}$ & $8.3^{\mathrm{d}}$ & $4.1^{\mathrm{d}}$ & $15.8 \mathrm{e}$ & $63.7 c$ & $8.1^{b}$ & $91.9 \mathrm{c}$ \\
\hline & $-24 \mathrm{~L}$ & $6.4^{\mathrm{b}}$ & $1.2^{\mathrm{a}}$ & $1.3^{\mathrm{e}}$ & $22.8^{a}$ & $12.5^{\mathrm{a}}$ & $20.9 \mathrm{~b}$ & $34.9^{\mathrm{f}}$ & $7.7 \mathrm{~d}$ & $92.3^{a}$ \\
\hline & $-24 S$ & $5.4^{\mathrm{e}}$ & $\mathrm{Nd}$ & $2.5^{a}$ & $6.2^{\mathrm{e}}$ & $2.9 \mathrm{e}$ & $15.6 \mathrm{~g}$ & $67.4^{\mathrm{b}}$ & $7.9 c$ & $92.1^{b}$ \\
\hline & $-16 \mathrm{~L}$ & 7.1 $1^{\mathrm{a}}$ & $1.0^{\mathrm{b}}$ & $1.9^{\mathrm{d}}$ & $19.7 \mathrm{~b}$ & $10.1^{\mathrm{b}}$ & $20.1^{\mathrm{c}}$ & $40.1^{\mathrm{e}}$ & $9.0^{\mathrm{a}}$ & $91.0^{\mathrm{d}}$ \\
\hline & $-16 S$ & $5.6^{\mathrm{d}}$ & $\mathrm{Nd}$ & $2.3 c$ & $6.0^{\mathrm{f}}$ & $2.9 \mathrm{e}$ & $15.7^{\mathrm{f}}$ & $67.5^{\mathrm{a}}$ & $7.9 c$ & $92.1^{b}$ \\
\hline & $-10 \mathrm{~L}$ & $5.6^{\mathrm{d}}$ & $0.8^{c}$ & $2.3 c$ & $9.4^{c}$ & $6.3 c$ & $21.5^{\mathrm{a}}$ & $54.1^{\mathrm{d}}$ & $7.9 c$ & $92.1^{b}$ \\
\hline & $-10 S$ & $5.7 \mathrm{c}$ & $\mathrm{Nd}$ & $2.4^{\mathrm{b}}$ & $5.1 \mathrm{~g}$ & $2.7^{f}$ & $16.7^{\mathrm{d}}$ & $67.4^{\mathrm{b}}$ & $8.1^{\mathrm{b}}$ & $91.9 c$ \\
\hline
\end{tabular}

The same letters within column for total or sn-2 or sn-1,3 position are not significantly different $(\mathrm{p}<0.05) ;{ }^{*}-24 \mathrm{~L}$ is the liquid fraction obtained by fractionation at $-24^{\circ} \mathrm{C}$. Other fractions are similarly designated; $\uparrow$ nd means not detected; $¥ \Sigma$ SFA, total saturated fatty acids; $¥ \Sigma \mathrm{UFA}$, total unsaturated fatty acids. 
In conclusion, one purpose of this study was to obtain erucic acid reduced fractions because erucic acid has undesirable effect on human health when consumed in large amount. However, erucic acid could be attained in the solid fraction rather than the liquid fraction. The result demonstrated that better reduction of erucic acid would be possible by lowering temperature.

\section{REFERENCES}

Aaes-Jorgensen, E. 1972. Nutritional value of rapeseed oil, in Rapeseed Cultivation, Composition, Processing and Utilization, edn. by Appelqvist L-A and Ohlson R. Amsterdam: Elsevier Publishing Company. p. 301-353.

AOCS. 1990. Official Methods and Recommended Practise of the American Oil Chemist's Society. $4^{\text {th }}$ Ed., American Oil Chemist's Society. Champaign, IL.

Chong, C. N., Hoh, Y. M. and Wang, C. W. 1992. Fractionation procedures for obtaining cocoa butter-like fat from enzymatically interesterified palm olein. JAOCS. 69: 137-140.

Dwivedi, C., Muller, L. A., Goetz-Parten, D. E., Kasperson, K and Mistry, V. V. 2003. Chemopreventive effects of dietary mustard oil on colon tumor development. Cancer Lett. 196: 29-34.

Fernandez-Escober, J., Dominguez, J., Marti, A. and Fernandez-Martinez, J. M. 1988. Genetics of erucic acid content in interspecific hybrids of Ethiopian mustard (B. carinata $A$. Braun) and Raoeseed (B. napus L.). Plant Breeding. 100: 310-315.

Hamm, W. 1995. Trends in edible oil fraction. Trends. Food Sci. Technol. 6: 121-126.

Lee, K. T. and Akoh, C. C. 1996. Immobilized lipase-catalyzed production of structured lipids with eicosapentaenoic acid a specific positions. JAOCS. 73(5): 611-615.

Lee, K. T. and Foglia, T. A. 2001. Fractionation of menhaden oil and partially hydrogenated menhaden oil: characterization of triacylglycerol fractions. JAOCS. 78: 297-303.

Mayamol, P. N., Samuel, T., Balachandran, C., Sundaresan, A. and Arumughan, C. 2004. Zerotrans shortening using palm stearin and rice bran oil. JAOCS. 81: 407-413.

Pritchard, J. L. R. 1991. Analysis and properties of oilseeds. In: Rossell JB, Pritchard JLR. Analysis of oilseeds fats and fatty foods. London: Elsevier. p. 80-95.

Quinlan, P. and Moore, S. 1993. Modification of triacylglycerols by lipases: Process technology and its application to the production of nutritionally improved fats. INFORM. 4: 580-585.

SAS. 2002. User's Guide. SAS Institute, Inc. Cary, NC

Singh, R. B., Niaz, M. A., Sharma, J. P., Kumar, R., Rastogi, V. and Moshiri, M. 1997. Randomized double blind placebo controlled trial of fish oil and mustard oil in patients with suspected acute myocardial infarction: the Indian experiment of infarct survival 4, Carciovasc Drug Ther. 11: 485-491.

Webster, G. 1998. Small scale processing of vegetable oil for niche markets. Lipid Technol News. 4: 38-43.

Yu, F., Kim, S. H., Kim, N. S., Lee, J. H., Bae, D. H. and Lee, K. T. 2006. Composition of solventfractionated rice bran oil. J. Food Lipids. 13: 286-297. 